\title{
1 The energetics of social signaling during roost location in Spix's disc-winged
}

\section{2 bats}

3

4 Running title: Energy costs of calling in disc-winged bats

5

6 Gloriana Chaverri ${ }^{1,2, *}$, Paula Iturralde-Pólit ${ }^{1 \square}$, Natalia Ivone Sandoval-Herrera ${ }^{3 \square}$, Adarli

7 Romero-Vásquez ${ }^{4}$, Silvia Cháves-Ramírez ${ }^{5}$ and Maria Sagot $^{6}$

81 Sede del Sur, Universidad de Costa Rica, Golfito, CRI; 2 Smithsonian Tropical Research Institute, Balboa, Ancón,

$9 P A N ; 3$ Department of Ecology and Evolutionary Biology, University of Toronto, Ontario, CAN; 4 Escuela de

10 Biología, Universidad de Costa Rica, San Pedro, CRI; 5 Escuela de Biología, Universidad Nacional, Heredia, CRI;

116 Department of Biological Sciences, State University of New York at Oswego, New York, USA

12

13 *Author for correspondence. E-mail: gloriana.chaverri@ucr.ac.cr, Phone: 506-8385-7638

$14 \square$ : These authors contributed equally.

15

16

\section{Summary Statement}

18 Spix's disc-winged bats constantly produce contact calls while searching for roosts, which we

19 show significantly increases an individual's metabolic rate. 


\section{Abstract}

26 Long-term social aggregations are maintained by multiple mechanisms, including the use of

27 acoustic signals, which may nonetheless entail significant energetic costs. To date, however, no

28 studies have gauged whether there are significant energetic costs to social call production in bats,

29 which heavily rely on acoustic communication for a diversity of social tasks. We measure

30 energetic expenditure during acoustic signaling in Spix's disc-winged bats (Thyroptera tricolor),

31 a species that commonly uses contact calls to locate the ephemeral furled leaves that they use for

32 roosting. To determine the cost of sound production, we measured oxygen consumption using

33 intermittent-flow respirometry methods, with and without social signaling. Our results show that

34 the emission of contact calls significantly increases oxygen consumption; vocal individuals

35 spent, on average, $12.42 \mathrm{~kJ}$ more during social signaling trials than they spent during silent trials.

36 Furthermore, production of contact calls during longer periods increased oxygen consumption

37 for males but not for females. We also found that as resting metabolic rates increased in males,

38 there was a decreasing probability that they would emit response calls. These results provide

39 support to the "allocation model", which predicts that only individuals with lower self-

40 maintenance costs can afford to spend energy in additional activities. Our results provide a step

41 forward in our understanding of how physiology modulates behavior, specifically how the costs

42 of call production and resting metabolic rates may explain the differences in vocal behavior

43 among individuals.

45 Keywords: allocation model, bats, energetic expenditure, resting metabolic rate, social calls. 


\section{Introduction}

49 Many social animals rely on acoustic signals to facilitate social coordination (Kondo and

50 Watanabe 2009; Fichtel and Manser 2010). In bats, for example, social calls are used to locate

51 dependent young, mating partners, prompt and coordinate cooperative interactions, and/or

52 defend and announce the location of resources, including roosts (Chaverri et al. 2018). The latter

53 is of critical importance given that roosts provide refuge from predators and inclement weather,

54 and are the main sites where social interactions, such as lactation, grooming, and mating, occur

55 (Kunz 1982). Thus, the use of social calls during roost finding increases the probability of

56 engaging in beneficial social interactions while reducing the risks of predation; as such, these

57 acoustic signals represent a critical component of social living.

58 Despite our growing understanding of the benefits of social signaling, particularly in bats,

59 we still do not understand its costs in different contexts. Studies in other taxa suggest that

60 vocalizations that serve a social function increase an individual's risk of being detected by

61 predators (Magrath et al. 2010) or by potential prey (Deecke et al. 2005), which could reduce

62 foraging efficiency. Moreover, the production of acoustic signals may also carry significant

63 metabolic costs. For example, energy expenditure of vocalizing animals could be up to eight

64 times higher than those of silent ones (Ophir et al. 2010). In bats, echolocation calls produced

65 during flight carry no additional energetic costs beyond those required to power flight

66 (Speakman and Racey 1991; Voigt and Lewanzik 2012), yet may entail significant metabolic

67 costs when produced while roosting, likely due to the contraction of muscles involved in sound

68 emission (Dechmann et al. 2013). However, despite the costs of sound production, the benefits to

69 group coordination and roost-finding efficiency are significant, as just a few calls produced by a 
70 single roosting bat are enough to maintain group cohesion and decrease the time needed to locate

71 a new roost site (Sagot et al. 2018).

72 The costs of call production may potentially explain why social calls are not emitted

73 more frequently, in specific contexts, or by all group members. In moving groups, for example,

74 members may produce social calls only sporadically (Deecke et al. 2005), and individuals may

75 become silent altogether when faced with increased levels of predation risk (Abbey-Lee et al.

76 2016). The energetic costs of sound production may also explain why only some group members

77 vocalize, as has been observed in bats where lactating females produce significantly fewer calls

78 compared to non-reproductive and pregnant females (Chaverri and Gillam 2015). These

79 intraspecific differences suggest that vocalizations involve higher energetic costs and that non-

80 energetically limited individuals may be able to afford sound production for social

81 communication.

82 Here, we aim to estimate the energetic cost of social calling in roosting bats to understand

83 patterns of inter-individual differences in vocal behavior. We focus on Spix's disc-winged bat,

84 Thyroptera tricolor, a small insectivorous species that roosts in the developing tubular leaves of

85 plants in the order Zingiberales (Vonhof and Fenton 2004) in groups of approximately 5

86 individuals (Vonhof et al. 2004; Sagot et al. 2018). This species is known to use a call-and-

87 response contact calling system for maintaining very stable group composition (Chaverri 2010)

88 despite moving among roost-sites on a daily basis. Spix's disc-winged bats produce two different

89 types of social calls: the "inquiry" calls that are emitted by flying individuals and "response"

90 calls that are emitted by roosting individuals in response to inquiry calls to guide and attract their

91 conspecifics to the roosts (Chaverri et al. 2010). In this species, the rates of response call

92 production are relatively consistent within, but vary widely among individuals (Chaverri and 
93 Gillam 2015). Furthermore, social groups are composed by a combination of vocal and non-

94 vocal bats in the context of response calling, and thus around $50 \%$ of individuals produce

95 response calls upon hearing inquiry calls from group and non-group members, whereas the rest

96 never vocalize (Chaverri and Gillam 2015; Sagot et al. 2018).

97 We simulate vocal exchanges in T. tricolor to gauge the energetic costs of response call

98 production. If individuals actively respond to the inquiry calls of their conspecifics, we expect

99 metabolic rates to increase significantly; specifically, oxygen consumption should increase when

100 bats vocalize for longer periods of time, as studies in a number of taxa demonstrate that

101 vocalizations increase energy expenditure (Ryan 1988; Oberweger and Goller 2001; Ophir et al.

102 2010). We also test whether resting metabolic rates (RMR), i.e. those that reflect the metabolic

103 rate of an individual during its inactive period ( $\mathrm{McNab} 1997)$, correlate with response call

104 production. Previous studies suggest that levels of activity or aggressiveness, which are traits that

105 allow us to distinguish among animal personalities, are either positively or negatively influenced

106 by resting metabolic rates (Careau et al. 2008). In the first case, termed the "performance

107 model", animals with greater levels of activity or aggression require larger organs to sustain

108 these traits, and thus have higher-than-average maintenance costs (Daan et al. 1990). In contrast,

109 the "allocation model" predicts a negative relationship between RMR and activity or

110 aggressiveness because when food is limited, only individuals with lower self-maintenance costs

111 can afford to spend energy in additional activities (Careau et al. 2008). While we have no a priori

112 expectation regarding which model, performance or allocation, may predict response calling

113 rates in T. tricolor, we test this to increase our understanding of the factors that may explain

114 vocal personalities in the context of social communication. 


\section{Methods}

117 We collected data on metabolic rates for 38 individuals (18 adult females, 10 adult males, 3

118 subadult females, 4 subadult males and 3 juvenile males) from 11 social groups (i.e., individuals

119 using the same roost at the same time) at Barú Biological Station in Southwestern Costa Rica, in

120 July 2017. To find groups, we searched Heliconia spp., Calathea spp. and Musa spp. furled

121 leaves, commonly used by T. tricolor as roosting sites (Vonhof and Fenton 2004). Once we

122 located a roost, we captured all group members and placed them inside a cloth holding bag to

123 bring them to the laboratory. Back in the laboratory, we weighted all the individuals and

124 measured their forearm lengths (as a measure of body length). We also sexed, aged, and

125 determined the reproductive condition for all bats captured.

126 For each individual, we were interested in two parameters: 1) Resting Metabolic Rate

127 (RMR), and 2) metabolic rate while producing response calls. The animals were placed singly

128 inside a tubular structure made of transparent plastic; there they remained safely attached to the

129 interior's smooth surface. The tube and bat were then placed inside a metabolic chamber and let

130 to acclimate for $30 \mathrm{~min}$. We measured the bats' oxygen consumption using the methods

131 described below, resting and while listening/responding to conspecific inquiry calls. All

132 measurements were made in a silent room at ambient humidity $(70 \%)$ and temperature $\left(27^{\circ} \mathrm{C}\right)$

133 during daytime hours. At the end of the experiments, we provided mealworms (Tenebrio

134 molitor) and water ad libitum to all individuals before releasing them in the same area where

135 they were originally captured.

136 Thyroptera tricolor bats only produce response calls after an inquiry call has been

137 emitted, and do so primarily during the day (Chaverri et al. 2010); thus, we broadcasted

138 previously recorded inquiry calls to elicit response calling from the bats within the chamber. 
139 These inquiry calls were previously collected from five individuals flying within a large flight

140 cage $(3 \times 4 \times 9 \mathrm{~m})$ for a total of 1 minute; none of these individuals were later included in our

141 respirometry experiments. A total of 67 inquiry calls were identified in the 1-min recording, and

142 the playback was continuously run for 10 minutes through an UltraSoundGate Player to a

143 broadband loudspeaker (Ultrasonic Omnidirectional Dynamic Speaker Vifa, Avisoft

144 Bioacoustics) placed inside the chamber. We recorded response calls produced by the individuals

145 inside the chamber with an Avisoft condenser microphone (CM16, Avisoft Bioacoustics, Berlin,

146 Germany) through Avisoft's UltraSoundGate 116Hm onto a laptop computer running Avisoft-

147 Recorder software (sampling rate $384 \mathrm{kHz}, 16$-bit resolution), placed also inside the chamber.

148 We also video-recorded each of the trials to estimate the effect of movement (i.e. how long the

149 bats were actively moving during the trials) for better interpretation of the metabolic rate results.

151 Metabolic rate measurements

152 We measured $\mathrm{O}_{2}$ consumption $\left(\mathrm{VO}_{2}\right)$ of each individual using an intermittent-flow-through

153 respirometry. This set-up consisted of short-term trials (10 $\mathrm{min})$ of closed respirometry followed

154 by a flushing interval of 10 min that allowed the saturated air to be pumped out of the chamber

155 and replaced by new air, avoiding $\mathrm{CO}_{2}$ accumulation. This method was used instead of a flow-

156 through respirometry since it was not possible to measure flow rate. We placed each bat into a

157 2L acrylic chamber lined with paper to reduce sound disturbance (i.e., reduction of echo

158 interference from playback). Air was pumped into the chamber using a standard fish tank pump

159 and then drawn out and passed through a column of indicating Drierite TM connected to the

160 ML206 gas analyzer fed from a damped, micro-vacuum pump (200 mL/min; ADInstruments,

161 Bella Vista, NSW, Australia). Since we did not dry the air going into the chamber, we measured 
162 relative humidity of incurrent air with an electronic hygrometer, and mathematically scrubbed

163 water vapor to provide a $\mathrm{VO}_{2}$ corrected to standard temperature pressure dry (STPD). We

164 recorded the voltage outputs of the gas analyzer and thermocouple at a sampling frequency of 10

165 Hz using a PowerLab ML750 A/D converter (ADInstruments) and LabChart software

166 (ADInstruments). For each bat we recorded $\mathrm{O}_{2}$ consumption for 10-min intervals of closed

167 respirometry with and without sound broadcast. We calculated the whole individual metabolic

168 rate $\left(\mathrm{O}_{2} \mathrm{ml} \mathrm{h}^{-1}\right)$ using equation (4.9) of Lighton (2008), correcting for ambient pressure and

169 standard temperature afterwards.

$$
\dot{V} \mathrm{O}_{2}=\frac{\left(\mathrm{V} \text { chamber }-\mathrm{VH}_{2} \mathrm{O}\right)-\left[\mathrm{FiO}_{2}-\mathrm{FEO}_{2}\right.}{1-\mathrm{FEO}_{2} * 1-\mathrm{RQ}}
$$

170 where $\mathrm{V}$ chamber is the volume of the chamber calculated by subtracting an approximation of

171 the volume of the bat (mass multiply by 0.98$)$ to the actual volume of the chamber $(2 \mathrm{~L}), \mathrm{VH}_{2} \mathrm{O}$ is

172 the water vapor in the chamber; $\mathrm{FiO}_{2}$ and $\mathrm{FEO}_{2}$ are the fractional concentration of $\mathrm{O}_{2}$ at the start

173 and end of the experiment respectively. RQ is the respiratory quotient.

174 We converted oxygen consumption rate $\dot{V} \mathrm{O}_{2}$ into energy expenditure in kJ by utilizing

175 the oxy-joules equivalents $\left(\mathrm{MR}_{\mathrm{kj}}\right.$ in $\left.\mathrm{kJ} \mathrm{hr}^{-1}\right)$ according to the following equation from Lighton

176 (2008):

$$
M R_{k j}=V O_{2} \times[16+5.164(\mathrm{RER})] R E R=\frac{V C O_{2}}{V O_{2}}
$$

177 where RER is the respiratory exchange ratio $\left(\mathrm{VCO}_{2} / \mathrm{VO}_{2}\right)$. We assumed a RER of 0.77 ,

178 previously reported for insectivorous bats (Speakman et al. 1989b).

180 Mammalogists for capture, handling and care of mammals (Sikes 2016) and the ASAB/ABS

181 Guidelines for the use of animals in research. This study was conducted in accordance with the 
182 ethical standards for animal welfare of the Costa Rican Ministry of Environment and Energy,

183 Sistema Nacional de Áreas de Conservación, permit no. SINAC-ACOPAC-RES-INV-008-2017.

\section{Data Analyses}

186 We compared metabolic variables (i.e., RMR and energy expenditure during trials with sound)

187 among age categories using a one-factor ANOVA and Tukey comparisons at an alpha level of

188 0.10. We found significant differences in RMRs between juveniles and adults, but not between

189 adults and subadults $\left(\mathrm{F}_{2,35}=2.95, \mathrm{P}=0.01\right)$. Therefore, we merged data for the latter but

190 eliminated juveniles from further analyses. Our sample size for subsequent tests was 21 females

191 and 14 males.

192 To determine if males and females differed in the amount of time spent producing

193 response calls or moving, we conducted two separate Mann-Whitney U-tests, as the data were

194 non-normally distributed. We also ran a Chi-square test to determine if the proportion of vocal

195 (i.e., an individual that produced at least one response call) vs. non-vocal bats differed between

196 males and females. We then determined if males and females differed in resting metabolic rate

197 and metabolic rate while producing response calls with two separate independent samples t-tests.

198 We analyze data separately for males and females as previous studies have shown that the

199 strength and direction of selection on resting metabolic rates may differ according to sex (Burton

200 et al. 2011).

To test if more vocal bats (i.e., bats that vocalized for longer periods of time) had higher

202 metabolic rates, we conducted a linear model with energy expenditure in kilojoules (kJ) as the

203 response variable, sex as a fixed factor, and as regressors, we selected the time the bats spent 1)

204 moving, 2) producing response calls, 3) or other types of calls (echolocation, distress, and other 
205 calls of unknown function). We also included 4) mass as an additional regressor in the model.

206 We retained the strongest explanatory variables using backward elimination and ran analyses

207 separately for males and females. We also determined which was the variable with the greatest

208 explanatory value based on the CP Mallows. We generated Q-Q and predicted vs. residual plots

209 to test for normality and homogeneity of variances, respectively; both tests show that all

210 assumptions of the model were met. In our results, we include the estimates of the multiple

211 regression and those of simple regressions for explanatory variables kept in the model, to verify

212 if independent effects on $\mathrm{O}_{2}$ consumption are positive or negative.

213 To determine if RMR is related with the time bats spend producing response calls, we

214 conducted a generalized linear model with time spent producing response calls as the response

215 variable, and energy expenditure $(\mathrm{kJ})$ and sex (and their interaction) as fixed factors. The

216 dependent variable was non-normally distributed (Shapiro-Wilks tests $=$ all p-values $<0.001$ )

217 and could be modeled best by a negative binomial distribution ( $\mathrm{p}$-value $=0.17$ ).

218 Finally, we tested if sex and the propensity to produce response calls or not had an effect

219 on the difference in energy expenditure during resting trials and during trials with sound through

220 a general linear model. The difference in energy expenditure was estimated as the amount of kJ

221 consumed during trials with sound minus the amount of $\mathrm{kJ}$ consumed during trials without

222 sound. Bats were categorized as being vocal if they produced at least one response call during

223 our trials with sound.

\section{Results}

226 Bats were non-vocal during the 10-minute trials in which we measured the resting metabolic

227 rates, i.e., those for which no sounds were broadcast. However, for trials in which we broadcast 
228 inquiry calls, bats vocalized for an average of 27.47 seconds $(\mathrm{SD}=37.17)$; many individuals $(\mathrm{n}=$

229 11) were non-vocal while the rest produced various types of vocalizations for up to $125.42 \mathrm{~s}$.

230 Animals produced three distinct calls with known functions and in decreasing order of

231 frequency: response calls, which accounted for $61 \%$ of the time spent vocalizing; echolocation

232 calls, which accounted for $21 \%$; and distress calls (10\% of the time). In some occasions, bats

233 produced other calls with unknown function, which accounted for $8 \%$ of the time spent

234 vocalizing (Fig. 1). There was no difference in the time spent vocalizing between males and

235 females for any of the call types analyzed $(\mathrm{P}>0.13)$, nor was there a difference in the proportion

236 of vocal vs. non-vocal individuals between males and females (vocal females $=38 \%$, vocal

237 males $=43 \% ; \mathrm{P}=0.77$ ). Time spent moving was also not significantly different between males

238 and females $(\mathrm{P}=0.72)$.

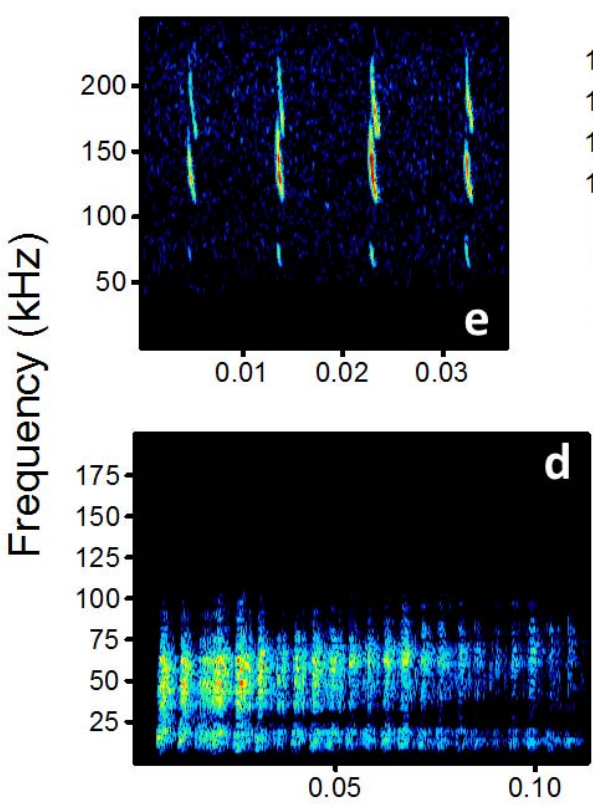

240

241 Fig. 1. Sonograms depicting exemplars of call types recorded during our 10-min respirometry

242 sessions: echolocation (e), response (r), distress (d), other (o).
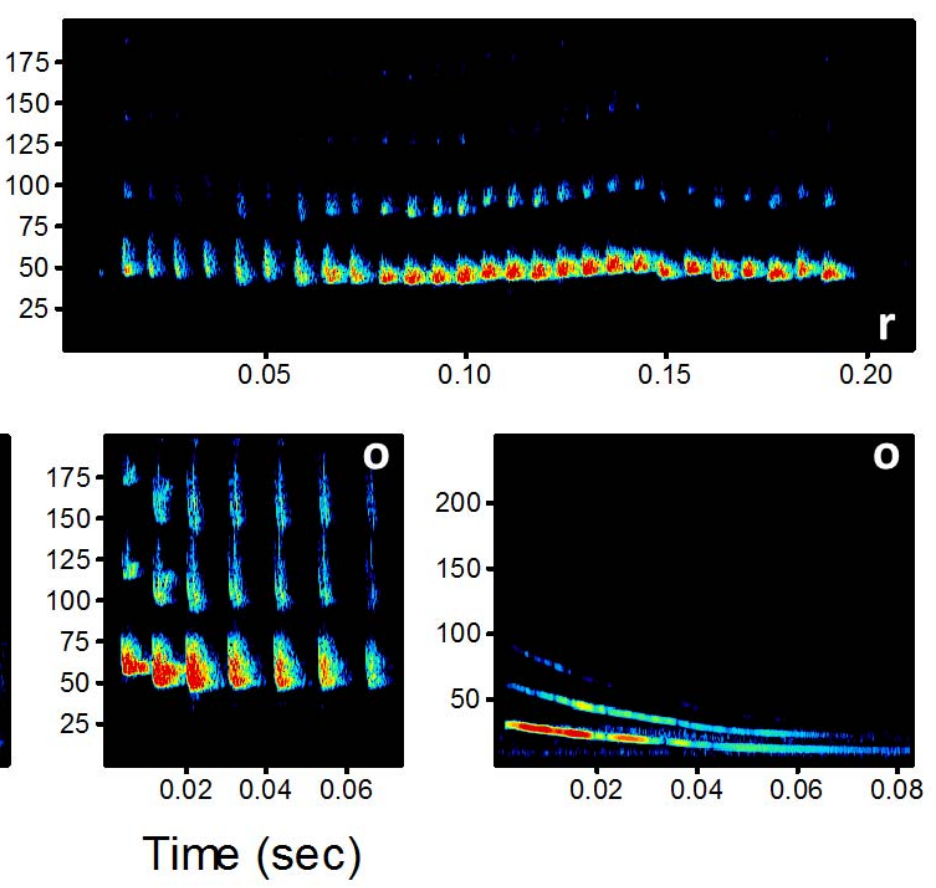
Animals consumed an average of $7.80 \mathrm{ml} \mathrm{O}_{2} \mathrm{~h}^{-1}$ during trials when no sounds were

245 emitted (Table 1). Females had a significantly greater energy expenditure $(\mathrm{kJ})$ during periods of

246 inactivity than males $(\mathrm{t}=2.57, \mathrm{p}=0.01)$. During the experiments with sound, bats consumed an

247 average of $16.93 \mathrm{ml} \mathrm{O}_{2} \mathrm{~h}^{-1}$. There was not a significant difference in energy expenditure (kJ)

248 between males and females during trials with sound $(\mathrm{t}=1.06, \mathrm{p}=0.29)$.

250 Table 1. Whole Animal Metabolic Rate $\left(\mathrm{ml} \mathrm{O}_{2} \mathrm{~h}^{-1}\right)$ during trials when inquiry calls were

251 broadcasted (sound) or when bats were resting (no sound).

\begin{tabular}{|c|c|c|c|c|c|}
\hline \multirow[b]{2}{*}{ Sex } & \multirow[b]{2}{*}{ Weight (g) } & \multicolumn{2}{|c|}{ Sound } & \multicolumn{2}{|c|}{ No sound } \\
\hline & & Range & Mean \pm SD & Range & Mean \pm SD \\
\hline Female & $4.50 \pm 0.40$ & $8.37-38.89$ & $17.94 \pm 7.40$ & $3.38-16.29$ & $8.86 \pm 3.62$ \\
\hline Male & $4.10 \pm 0.36$ & $4.80-30.13$ & $15.42 \pm 6.74$ & $2.30-10.95$ & $6.22 \pm 2.33$ \\
\hline All & $4.32 \pm 0.43$ & $4.80-38.89$ & $16.93 \pm 7.15$ & $2.30-16.29$ & $7.80 \pm 3.39$ \\
\hline
\end{tabular}

252

254 The results of our general linear model, where we tested if sex and being vocal had an

255 effect on the difference in energy expenditure during trials with sound compared to resting trials,

256 show that the latter factor (being vocal) had a significant effect $\left(\mathrm{F}_{1,31}=11.70, \mathrm{p}<0.01\right)$. The

257 average increase in energy expenditure for vocal bats during trials with sound was $12.42 \mathrm{~kJ}$

258 ( \pm 1.48$)$, whereas the increase for silent bats was $4.48( \pm 1.78$; Fig. 2$)$. Although the difference in

259 energy expenditure for vocal vs. non-vocal individuals was greater for males than for females,

260 neither sex nor the interaction between sex and vocal behavior was significant $(\mathrm{p}>0.25)$. 


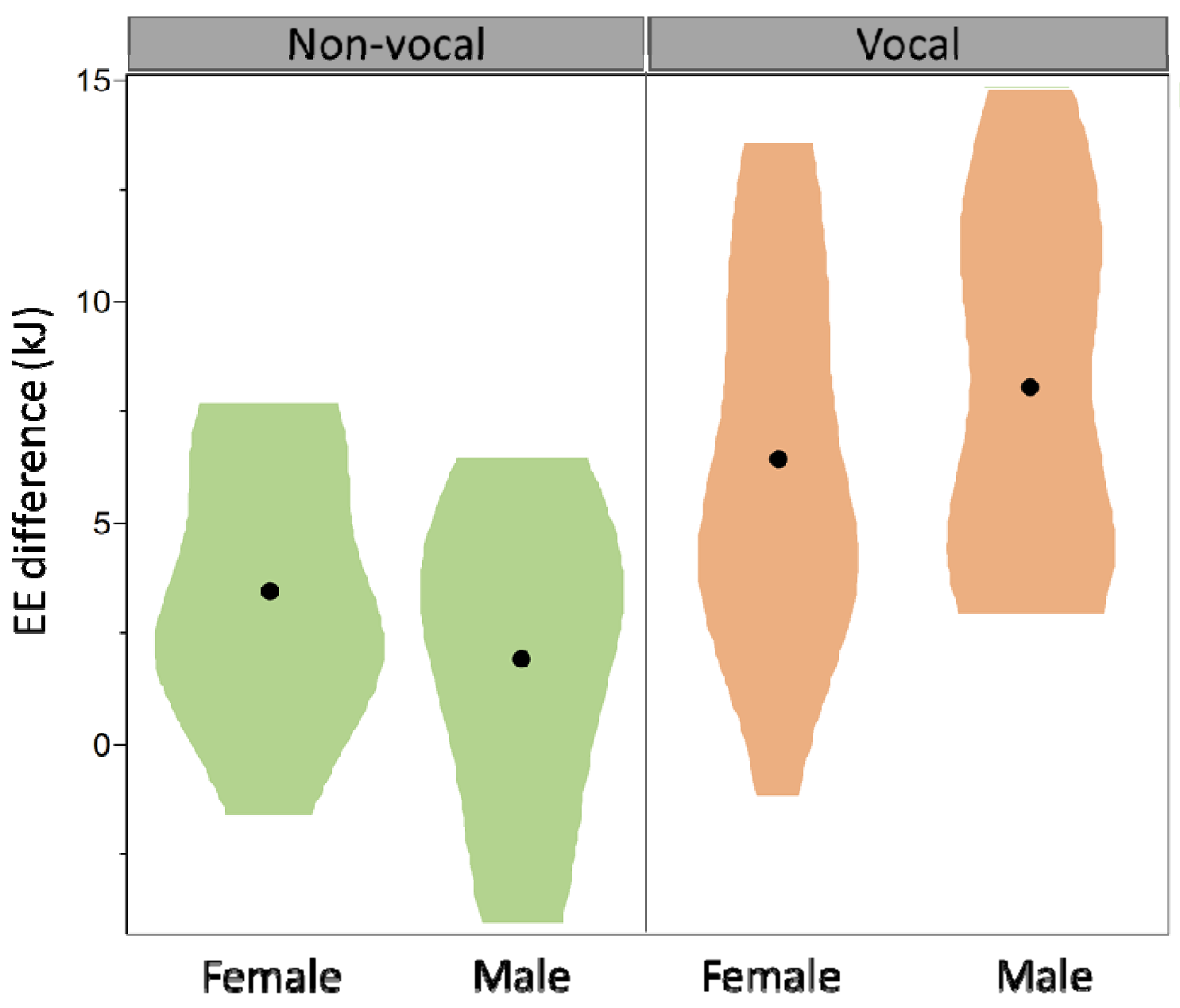

263 Fig. 2. Difference in energy expenditure, measured as the difference in kJ during trials with

264 sound minus kJ during trials without sound, for vocal and non-vocal males and females.

For females, our multiple linear regression model indicates that energy expenditure $(\mathrm{kJ})$

267 was significantly and positively influenced by the time spent producing calls, such as

268 echolocation and distress; however, time spent producing response calls did not affect their

269 energy expenditure, nor did time spent moving and body mass (Table 2, Fig. 3). In the model for

270 males, there was a significant and also positive effect of time spent producing response calls on

271 energy expenditure; thus, males that produced more response calls had greater energy 
14

272 expenditure. Time spent moving also contributed to an increase in energy expenditure in males

273 (Table 2, Fig. 3).

274

275 Table 2. Results of the multiple regression analysis with energy expenditure $(\mathrm{kJ})$ as the response

276 variable and several explanatory variables. We include the estimates of the multiple regression

277 (MR) as well as those of the simple linear regression (SR). The CP-Mallows indicates the

278 explanatory power of the variables included in the model.

\begin{tabular}{|c|c|c|c|c|c|c|}
\hline \multirow[b]{2}{*}{ Sex } & \multirow[b]{2}{*}{$\mathrm{R}^{2}$} & \multirow[b]{2}{*}{ Explanatory } & \multicolumn{2}{|c|}{ Estimate } & \multirow[b]{2}{*}{ P-value } & \multirow[b]{2}{*}{$\mathrm{CP}-$} \\
\hline & & & MR & SR & & \\
\hline & & & & & & Mallows \\
\hline Female & 0.49 & All calls except response (s) & 0.31 & 0.31 & $<0.001$ & 18.13 \\
\hline \multirow[t]{2}{*}{ Male } & 0.67 & Response (s) & 0.06 & 0.09 & 0.04 & 6.17 \\
\hline & & Move (min) & 0.80 & 1.15 & 0.02 & 7.26 \\
\hline
\end{tabular}




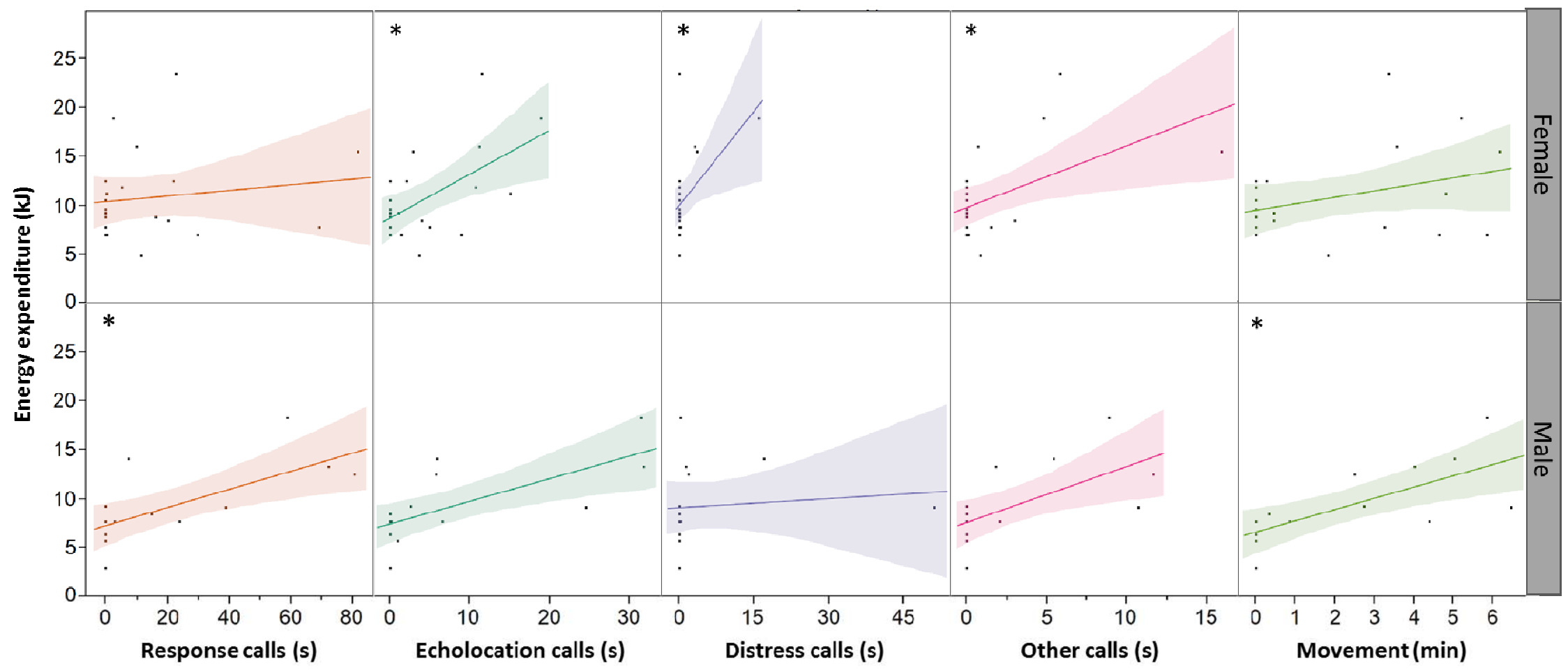

Fig. 3. Scatter plots showing the relationship between time invested in various activities (emission of several types of calls and

290 movement) and energy expenditure. Upper plots show the results for females and lower plots results for males. Asterisks indicate

291 significant relationships according to the multiple regression analysis (see table 2). 
Time spent producing response calls was significantly influenced by the interaction

293 between sex and RMR $\left(F_{1,31}=5.05\right.$, p-value $\left.=0.03\right)$, according to our generalized linear model.

294 When performing the model separately for males and females, the relationship between RMR

295 and time producing response calls for females was non-significant ( $\mathrm{p}$-value $=0.65$ ), whereas for

296 males the relationship was negative and significant (p-value =0.003; Fig. 4). Thus, as RMR

297 decreases in males, there is an increasing probability that they will emit response calls for longer

298 periods of time.

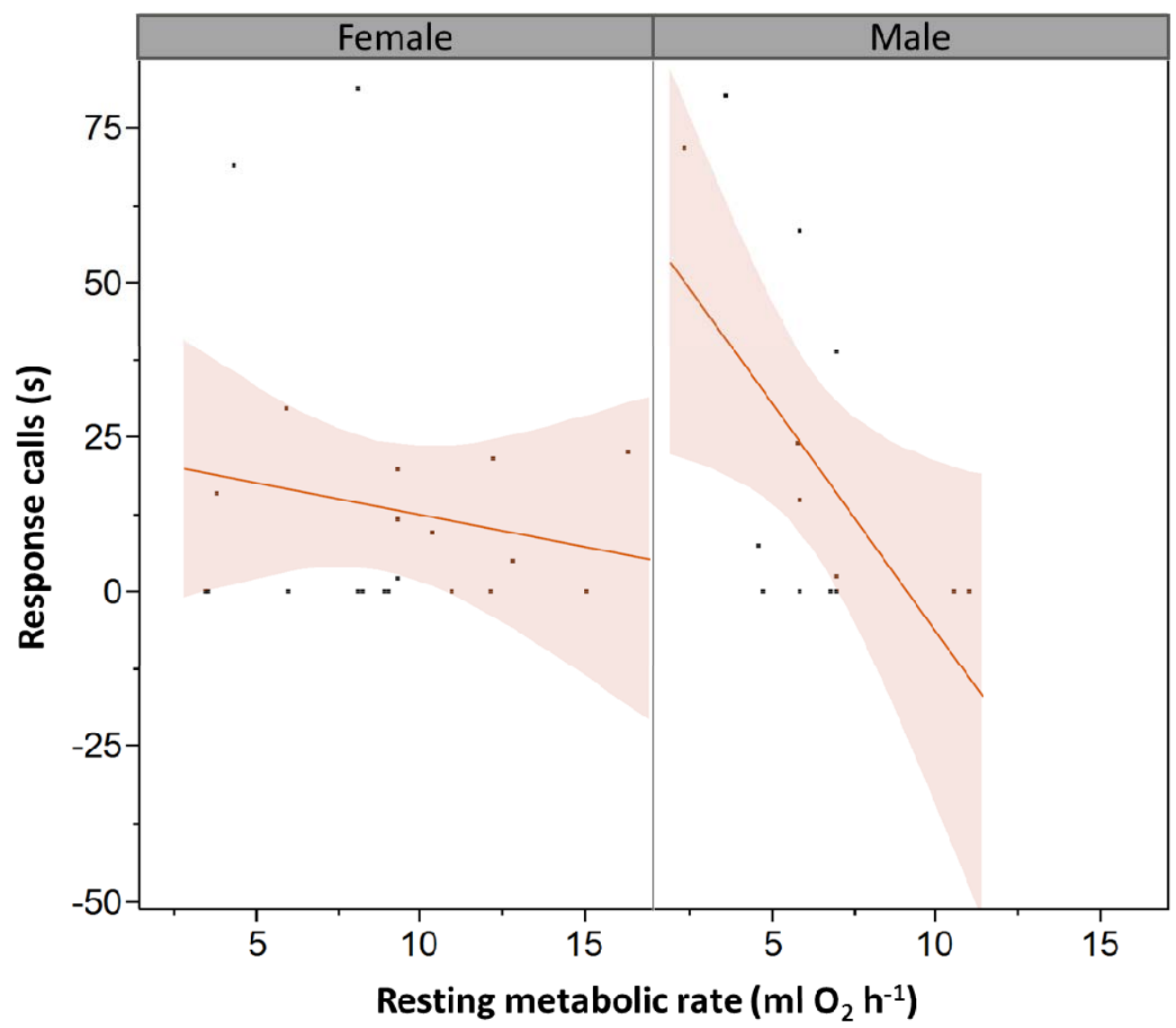

Fig. 4. Relationship between RMR and the time spent producing response calls (in seconds) for males and females. The shaded area around the trendline shows the $95 \%$ confidence interval. 


\section{DISCUSSION}

305 Our results demonstrate that the production of social calls that are used to indicate the position of

306 a roost site increases the energetic expenditure of bats. By producing even just one response call

307 upon hearing an inquiry call, individuals significantly increased their resting metabolic rate. For

308 males, the time spent producing response calls had a positive effect on energy expenditure,

309 which did not occur in females, despite the fact that males and females produced a similar

310 number of response calls and both were vocal in similar proportions. Vocal females increased

311 their metabolic rate, on average, 1.4-fold when producing response calls, whereas males

312 experienced a 3.2-fold increase.

Vocal communication can be observed in every major taxonomic group and in virtually

314 every environment, and it is energetically demanding for many species (Ryan 1988; Prestwich

315 1994; Oberweger and Goller 2001). Birds, for instance, increase their metabolic rate at least 2.5-

316 fold when producing courtship calls, while ectotherms such as insects and amphibians can

317 exhibit an 8-fold increase (Ophir et al. 2010). This is because sound production elevates

318 muscular activity (Prestwich 1994; Gillooly and Ophir 2010), and increases the vibration

319 frequency of the muscles that produce the sounds, elevating metabolic rates (Skoglund 1961;

320 Martin 1971; Elemans et al. 2004). In T. tricolor, both males and females significantly increased

321 their metabolic rates while producing response calls, suggesting that energetically compromised

322 bats cannot afford extra energy expenditures in functions that are not part of their normal daily

323 maintenance activities. This might help us explain why many individuals are non-vocal

324 (Chaverri and Gillam 2015; Sagot et al. 2018). Furthermore, in males but not in females, the

325 increase in metabolic rate was proportional to the time spent vocalizing, suggesting that males

326 that are energetically limited cannot produce response calls, or can only vocalize for short 
327 periods of time. This is possibly the reason why, in our study, only a small proportion of males

328 produced vocalizations during relatively large amounts of time. This has also been found in other

329 species such as bottlenose dolphins and birds, in which oxygen consumption increases with song

330 duration and call rate (Oberweger and Goller 2001; Franz 2003; Noren et al. 2013).

Although sound production can be energetically demanding, in some species this activity

332 does not increase an individual's metabolic rate (Ilany et al. 2013). For example, male hyraxes

333 (Procavia capensis) that sing more, counterintuitively conserve more energy. Likewise,

334 echolocating bats do not significantly increase their energy expenditure during flight (Speakman

335 et al. 1989a; Voigt and Lewanzik 2012). However, even when vocalizations are not energetically

336 demanding, they can still be considered a handicap (Gil and Gahr 2002). This is because

337 producing these signals requires time, learning and specialized structures, and it can increase the

338 chances of being detected by prey and predators (Koren and Geffen 2009; Charlton et al. 2011;

339 Wyman et al. 2012).

340 We also found that differences in RMRs may predict the time spent producing response

341 calls in males. Specifically, we found that males with lower RMRs emit response calls during

342 longer periods of time. These results confirm that levels of activity, in our case measured through

343 the time spent vocalizing, are negatively influenced by RMR, which provides support for the

344 allocation model. This model predicts that only individuals with lower self-maintenance costs

345 can afford to invest part of their daily energy budget in additional activities (Careau et al. 2008).

346 Despite our results, the most common trend in vertebrates is for RMR to positively influence

347 activity, thus supporting the performance model; however, males often exhibit the opposite

348 trend, which might indicate that they produce signals with enough energy to experience a trade-

349 off between RMR and activity (Stoddard and Salazar 2011). This latter argument might explain 
350 the differences in energetic expenditure during response calling observed for males and females

351 in our study. For instance, response calls in males might not only play a role in cooperative

352 signaling of roost location (Chaverri and Gillam 2010), but may also function for mate attraction;

353 if so, males could be under strong selection to produce high quality/energy calls as an honest

354 signal of their body size and condition (Schuchmann and Siemers 2010). Thus, the physiological

355 explanation for the differences in energetic costs of social signaling between males and females

356 could be hormonal, as several studies demonstrate that male sexual hormones significantly alter

357 the relationship between resting metabolic rates and signal quality or levels of activity (Wikelski

358 et al. 1999; Lynn et al. 2000; Buchanan et al. 2001). Future studies should try to confirm the link

359 between acoustic features of social calls like maximum energy, metabolic cost and mating

360 success, in addition to addressing the potential role of response calls for mate attraction in $T$.

361 tricolor.

In conclusion, our study demonstrates for the first time that social calls increase energetic

363 expenditure in bats. Given that bats depend so strongly on acoustic signals for modulating

364 multiple social activities (Gillam and Fenton 2016; Chaverri et al. 2018), our findings suggest

365 that energetic trade-offs may be of particular importance to understanding communication in this

366 group of mammals. The results of our study will surely extrapolate to various other species in

367 diverse contexts; however, it is the differences among systems that seem most fascinating. In our

368 case, we have addressed the costs of acoustic signaling during contact calling, but further studies

369 could reveal interesting tradeoffs for signals such as those employed between mothers and

370 offspring, or between males and females in the context of mate attraction, among others. Finally,

371 our results provide a step forward in our understanding of how physiology modulates behavior.

372 For example, many studies demonstrate that there is a link between resting metabolic rates and 
373 various personality traits (Careau et al. 2008; Careau and Garland 2015). Incorporating

374 physiological trade-offs to studies of animal personalities in the context of communication may

375 allow us to understand many aspects of social aggregations, including social roles and

376 communication networks.

\section{Acknowledgements}

379 The authors would like to thank Tenaja Smith-Butler and Cayla Turner for their help during field

380 work and for video analyses, and Ronald Villalobos for logistics support. We also thank Julio

381 Bustamante and Lilliana Rubí Jimenez for their help during research permit application. Finally,

382 we thank the Centro Biológico Hacienda Barú for their continuous support of our research.

384 Competing interests

385 The authors declare no competing or financial interests.

387 Data availability

388 The data supporting this article are available from the Figshare Digital Repository:

389 https://doi.org/10.6084/m9.figshare.13003805.v1.

$391 \quad$ References

392 Abbey-Lee RN, Kaiser A, Mouchet A, Dingemanse NJ (2016) Immediate and carry-over effects 393 of perceived predation risk on communication behavior in wild birds. Behav Ecol 27:708394 716. doi: 10.1093/beheco/arv210

395 Buchanan KL, Evans MR, Goldsmith AR, et al (2001) Testosterone influences basal metabolic 
rate in male house sparrows: A new cost of dominance signalling? Proc R Soc B Biol Sci 268:1337-1344. doi: 10.1098/rspb.2001.1669

398 Burton T, Killen SS, Armstrong JD, Metcalfe NB (2011) What causes intraspecific variation in 399 resting metabolic rate and what are its ecological consequences? Proc. R. Soc. B Biol. Sci.

400 Careau V, Garland T (2015) Energetics and behavior: many paths to understanding. Trends Ecol $401 \quad$ Evol 30:365-366. doi: 10.1016/j.tree.2015.04.007

402 Careau V, Thomas D, Humphries MM, Reale D (2008) Energy metabolism and animal 403 personality. Oikos 117:641-653. doi: 10.1111/j.0030-1299.2008.16513.x

404 Charlton BD, Ellis WAH, McKinnon AJ, et al (2011) Cues to body size in the formant spacing 405 of male koala (Phascolarctos cinereus) bellows: honesty in an exaggerated trait. J Exp Biol $406 \quad 214: 3414-3422$. doi: 10.1242/jeb.061358

407 Chaverri G (2010) Comparative social network analysis in a leaf-roosting bat. Behav Ecol $408 \quad$ Sociobiol 64:1619-1630

409 Chaverri G, Ancillotto L, Russo D (2018) Social communication in bats. Biol Rev 93:1938$410 \quad$ 1954. doi: $10.1111 /$ brv. 12427

411 Chaverri G, Gillam EH (2015) Repeatability in the contact calling system of Spix's disc-winged 412 bat (Thyroptera tricolor). R Soc Open Sci 2:140197. doi: 10.1098/rsos.140197

413 Chaverri G, Gillam EH (2010) Cooperative signaling behavior of roost location in a leaf-roosting 414 bat. Commun Integr Biol 3:1-4

415 Chaverri G, Gillam EH, Vonhof MJ (2010) Social calls used by a leaf-roosting bat to signal 416 location. Biol Lett 6:441-444. doi: 10.1098/rsbl.2009.0964

417 Daan S, Masman D, Groenewold A (1990) Avian basal metabolic rates: their association with 418 body composition and energy expenditure in nature. Am J Physiol 259:R333-40. doi: 
420 Dechmann DKN, Wikelski M, van Noordwijk HJ, et al (2013) Metabolic costs of bat

421 echolocation in a non-foraging context support a role in communication. Front Physiol 4:66.

422 doi: 10.3389/fphys.2013.00066

423 Deecke VB, Ford JKB, Slater PJB (2005) The vocal behaviour of mammal-eating killer whales:

424 Communicating with costly calls. Anim Behav 69:395-405. doi:

425 10.1016/j.anbehav.2004.04.014

426

427

428

429

430

431

432

433

434

435

436

437

438

439

440

441

Elemans CPH, Spierts ILY, Müller UK, et al (2004) Superfast muscles control dove's trill.

$$
\text { Nature 431:146-146. doi: 10.1038/431146a }
$$

Fichtel C, Manser M (2010) Vocal communication in social groups. In: Kappeler PM (ed)

Animal Behaviour: Evolution and Mechanisms. Springer Berlin Heidelberg, Berlin, pp 2954

Franz M (2003) Respiratory patterns and oxygen consumption in singing zebra finches. J Exp Biol 206:967-978. doi: 10.1242/jeb.00196

Gil D, Gahr M (2002) The honesty of bird song: Multiple constraints for multiple traits. Trends Ecol Evol 17:133-141. doi: 10.1016/S0169-5347(02)02410-2

Gillam EH, Fenton MB (2016) Role of Acoustic Social Communication in the Lives of Bats. In: Fenton MB, Grinnell A (eds) Bat Bioacoustics. Springer, New York, NY., pp 117-139

Gillooly JF, Ophir AG (2010) The energetic basis of acoustic communication. Proc R Soc BBiological Sci 277:1325-1331. doi: 10.1098/rspb.2009.2134

Ilany A, Barocas A, Kam M, et al (2013) The energy cost of singing in wild rock hyrax males: evidence for an index signal. Anim Behav 85:995-1001. doi: 10.1016/j.anbehav.2013.02.023 
442 Kondo N, Watanabe S (2009) Contact calls: Information and social function. Jpn Psychol Res

443 51:197-208. doi: 10.1111/j.1468-5884.2009.00399.x

444 Koren L, Geffen E (2009) Complex call in male rock hyrax (Procavia capensis): A multi-

445 information distributing channel. Behav Ecol Sociobiol 63:581-590. doi: 10.1007/s00265-

$446 \quad$ 008-0693-2

447 Kunz TH (1982) Roosting ecology of bats. In: Kunz TH (ed) Ecology of Bats. Plenum Press,

$448 \quad$ New York, pp 1-50

449 Lighton JRB (2008) Measuring Metabolic Rates: A Manual for Scientists. Oxford University

$450 \quad$ Press

451 Lynn SE, Houtman AM, Weathers WW, et al (2000) Testosterone increases activity but not daily

452 energy expenditure in captive male dark-eyed juncos, Junco hyemalis. Anim Behav 60:581-

$453 \quad$ 587. doi: $10.1006 /$ anbe. 2000.1510

454 Magrath RD, Haff TM, Horn AG, Leonard ML (2010) Calling in the Face of Danger: Predation

455 Risk and Acoustic Communication by Parent Birds and Their Offspring. In: Brockmann, HJ

456 and Roper, TJ and Naguib, M and WynneEdwards, KE and Mitani, JC and Simmons L (ed)

457 Advances in the Study of Behavior. pp 187-253

458 Martin WF (1971) Mechanics of sound production in toads of the genus Bufo: Passive elements.

$459 \quad$ J Exp Zool 176:273-293. doi: 10.1002/jez.1401760304

460 McNab BK (1997) On the Utility of Uniformity in the Definition of Basal Rate of Metabolism.

$461 \quad$ Physiol Zool 70:718-720. doi: 10.1086/515881

462 Noren DP, Holt MM, Dunkin RC, Williams TM (2013) The metabolic cost of communicative

463 sound production in bottlenose dolphins (Tursiops truncatus). J Exp Biol 216:1624-1629.

464 doi: $10.1242 /$ jeb.083212 
465 Oberweger K, Goller F (2001) The metabolic cost of birdsong production. J Exp Biol 204:3379_ $466 \quad 88$

467 Ophir AG, Schrader SB, Gillooly JF (2010) Energetic cost of calling: general constraints and 468 species-specific differences. J Evol Biol 23:1564-1569. doi: 10.1111/j.1420-

$469 \quad 9101.2010 .02005 . x$

470 Prestwich KN (1994) The energetics of acoustic signaling in anurans and insects. Integr Comp

$471 \quad$ Biol 34:625-643. doi: 10.1093/icb/34.6.625

472 Ryan MJ (1988) Energy, calling, and selection. Am Zool 855-898

473 Sagot M, Schöner CR, Jago AJ, et al (2018) The importance of group vocal behaviour in roost $474 \quad$ finding. Anim Behav 142:157-164

475 Schuchmann M, Siemers BM (2010) Variability in Echolocation Call Intensity in a Community 476 of Horseshoe Bats: A Role for Resource Partitioning or Communication? PLoS One 477 5:e12842. doi: 10.1371/journal.pone.0012842

478 Sikes RS (2016) 2016 Guidelines of the American Society of Mammalogists for the use of wild 479 mammals in research and education. J Mammal 97:663-688. doi:

$480 \quad 10.1093 /$ jmammal/gyw078

481 Skoglund C (1961) Functional analysis of swim-bladder muscles engaged in sound production of 482 the toadfish. J Biophys Biochem Cytol 10:187-200

483 Speakman JR, Anderson ME, Racey PA (1989a) The energy cost of echolocation in pipistrelle 484 bats (Pipistrettus pipistrellus). J Comp Physiol A 165:679-685. doi: 10.1007/BF00610999 485 Speakman JR, Anderson ME, Racey PA (1989b) The energy cost of echolocation in pipistrelle 486 bats ( Pipistrellus pipistrellus). J Comp Physiol A 165:679-685

487 Speakman JR, Racey PA (1991) No Cost of Echolocation for Bats in Flight. Nature 350:421-423 


\section{5}

488 Stoddard PK, Salazar VL (2011) Energetic cost of communication. J Exp Biol 214:200-205. doi:

$489 \quad 10.1242 /$ jeb.047910

490 Voigt CC, Lewanzik D (2012) "No cost of echolocation for flying bats" revisited. J Comp

$491 \quad$ Physiol B-Biochemical Syst Environ Physiol 182:831-840

492 Vonhof MJ, Fenton MB (2004) Roost availability and population size of Thyroptera tricolor, a

493 leaf-roosting bat, in northeastern Costa Rica. J Trop Ecol 20:291-305

494 Vonhof MJ, Whitehead H, Fenton MB (2004) Analysis of Spix’s disc-winged bat association

495 patterns and roosting home ranges reveal a novel social structure among bats. Anim Behav

$496 \quad 68: 507-521$

497 Wikelski M, Lynn S, Breuner C, et al (1999) Energy metabolism, testosterone and corticosterone

498 in white-crowned sparrows. J Comp Physiol - A Sensory, Neural, Behav Physiol 185:463-

499 470. doi: $10.1007 / \mathrm{s} 003590050407$

500 Wyman MT, Mooring MS, McCowan B, et al (2012) Acoustic cues to size and quality in the

$501 \quad$ vocalizations of male North American bison, Bison bison. Anim Behav 84:1381-1391. doi:

$502 \quad$ 10.1016/j.anbehav.2012.08.037

503

504 